\title{
Conclusions-and a proposed pattern for re-organization
}

\author{
B. T. O'CONNOR \\ M.S., M.Ch.Orth., F.R.C.S., F.R.A.C.S. \\ Director of the Institute of Orthopaedics
}

$\mathrm{Mr} O$ 'Connor was present throughout the Conference and has since, after a study of the Proceedings, contributed his own conclusions and proposals.

IN his opening remarks, Mr Kay explained that this symposium was born out of concern, in the minds of young trainees in orthopaedics and accident surgery, at the crisis in organization and staffing of 'casualty services' and further concern at the varying proposals from bodies large and small, powerful and weak, as to the solution of this problem.

The situation is clearly desperate! One can understand, therefore, that the Department of Health and Social Security, rightly sensitive to public opinion and to public rights, must take steps to meet the crisis. Doctor Bainbridge, representing the Department, has presented, clearly, the case for the Department's decision to meet this crisis with the appointment, on the basis of carefully prepared job-descriptions, of thirty to forty consultant casualty surgeons. These men will probably be drawn from the ranks of men like $\mathrm{Mr}$ Caro and other members of the Casualty Surgeons' Association.

There can be no doubt that Mr Caro's contributions to the organization of a casualty department, particularly in the context of a large conurbation such as London, has the admiration of all who treat the sick and the injured. Mr Caro, by his frank explanation of the origins of his organization and his unbiased contribution to the discussion, brings home the realization that men like him are giving sterling service.

However, we must ask ourselves whether this is the entire story. Clearly it is not! Regrettably the Department of Health and Social Security's decision fails to face the problem of complete reorganization, which is so badly needed and which is the key to the entire problem. Moreover, it fails completely to provide the lock for that organizational key, namely, staffiing at junior level.

This is clearly demonstrated by the irrefutable fact of Mr Durbin's survey. He has shown that, if one new consultant is provided for every department in the nation the cost will increase by $50 \%$ whilst the available manpower will rise by a mere $4 \frac{1}{2} \%$.
Mr Durbin went on to say that the crisis is due to unattractive salaries and hours of work for senior house officers who are largely immigrants and who are entering the country in lesser numbers. To some small extent he is right, but, one doubts that money and hours of work are the discouraging factors. It is the nature of the post, the lack of job satisfaction and the lack of belonging to a specific department with a realistic career structure, which discourages potential applicants for these posts.

These men move from post to post as casualty officers and are 'nobody's boys'. Lucky ones may be part of an orthopaedic and/or general surgical rotation. Even these people spend far too long in the emergency reception areas. The unlucky ones drift from job to job in the limbo of casualty officer posts.

It seems that the Department of Health and Social Security would have us believe that they can be delivered out of this limbo by the simple introduction of a consultant casualty surgeon who will train them and find a career structure for them. However, most of these men have no wish to be casualty surgeons. They desire a career in one of the more definitive specialties. Apart from those who would take any kind of post rather than return to their respective native lands, few would obtain real job satisfaction in such posts. This is true despite the complacency of some regional boards and some hospitals who boast of the number of applicants they have had for such posts when advertised. These people fail to realize that the desire for consultantship at all costs and for permanent employment does not equate with job satisfaction.

Another myth which should be scotched, is the belief that the crisis is due to a reduction in the numbers of immigrant doctors entering the country. It is really due to the fact that immigrant doctors are wiser and more discerning in their search for training and job satisfaction.

Mr Durbin went on to suggest that the staffing crisis might be met from the ranks of general practitioners. In the next breath he admits that the general practitioners are not interested. This was candidly endorsed by Dr Cull.

One must ask, why should the general practitioners show interest in such tasks within our 
present organizational structure? Clearly, the general practitioner is quite right in not wishing to assume the role of a Jack of all trades or a triage expert, that the unenviable casualty officer holds today. Provide the general practitioner with a proper organizational structure by means of general practitioner departments in large hospitals or by welldesigned health centres and he might show some interest.

Clearly, there are two basic problems, the key being re-organization and the lock for that key being the provision of a rational staffing structure.

When organization is mentioned, a lot is made of the difference imposed by geography, population, size of town etc. There are certainly such differences but they do not negate the need for a basic organizational pattern or model.

Patients may be different but they are rarely if ever unique. Similarly, organizational problems may be different but the modern techniques of systems analysis and operational research have shown us that they are never unique. From this one infers, with justification, that one basic simple pattern of organization can be provided for the nation. This model or organizational template can then be adapted, modified, moulded or welded to meet the specific requirements of an area, providing those specific requirements have been first determined by means of a careful systems study of the problem.

$\mathrm{Mr}$ Denham, in his paper, demonstrated that success in organization can be achieved with a do-ityourself systems study and management survey. He has analysed his problem, devised a basic model of organization similar to that created in Oxford and to that recommended by the Accident Service Review Committee, modified this model to suit his particular needs, and made it work. Surely, this is not beyond the wit of all those other centres who loudly bemoan their problem to the government, to the profession and to the public at large.

If the orthopaedic fraternity, the British Orthopaedic Association, the Department and the Regional Hospital Boards, working together had, like Mr Denham, made planned determined efforts to follow the systems laid down by the Accident Service Review Committee, the existing situation would be much less desperate.

Analysing the subject matter of this symposium, I have, to some extent, acted as the devil's advocate regarding the proposals put forward by the various speakers. I have tried to introduce support or criticism when I thought each was justified and also in the light of how I see the problem myself.

The problem, to my mind, resolves itself into two of the basic facets of any management system:

(1) Organization.

(2) Staffing.

\section{Organization}

Analysis of the problem down to its 'grass roots' and the creation of a new and very basic organizational module is the first step. In creating this module it must be appreciated that it is high time that the hospital, as a corporate body, assumes responsibility for those who seek aid within its portals, unheralded by appointments, by letters of referral or what-have-you.

No longer can the vortex of disorganization known as the casualty department be accepted. No longer can the hospital as a corporate body delegate the responsibility of this area to the orthopaedic and accident surgeons or, indeed, to any other 'mug' who has been, or is, foolish enough to assume responsibility for the reception of the sick at large.

Orthopaedic and accident surgeons and, particularly, those being trained today, are capable of and are prepared to take responsibility for the entire spectrum of minor and major trauma. Naturally, they will seek advice from other colleagues on special problems, but they will and can take responsibility for the organization and staffing of the trauma services.

What the orthopaedic and accident surgeons rightly cannot and will not do, if they have any sense, is to be responsible for the reception and resuscitation of general surgical and general medical emergencies. It is high time that our general surgical and physician colleagues took responsibility for the reception of the emergency problems relevant to their specialties. Moreover, it is time that they contributed to the staffing, at all levels, of the reception areas for their own particular emergencies.

Finally, the orthopaedic and accident services of the future will, quite rightly, assume no responsibility for the reception and treatment of those increasing numbers of casual or general practice type attendances. It is the responsibility of the hospital administration to realize the demands on its resources in this particular sphere and to provide the organization and staffing to meet that demand. This can, in large towns, which are those most affected by this specific demand, be separate and distinct from the true emergency reception areas of trauma, general medicine and general surgery.

Thus, it will be seen that the problem of unheralded attendance at hospital resolves itself into four main input channels:

Channel 1-Trauma.

Channel 2-General medicine including psychiatry.

Channel 3-General surgery including gynaecology and obstetrics.

Channel 4-General practice type cases.

Channel 1 will carry the heaviest load in most 
areas but in large towns Channel 4 may carry the largest load. Rarely, notwithstanding the report of the Royal College of Physicians, Channel 2 will carry the heaviest load.

However, percentage variation in channel load makes absolutely no difference to the basic organizational model. One simply adapts the model to suit local demands in channel load.

Moreover, one should ideally separate the reception areas for each channel in so far as the economics of shared and common services such as X-ray allow.

In point of fact, there is absolutely no need for Channel 4 to be anywhere near Channels 1, 2 and 3. The clients of Channel 4 are all of the non-acute type who can be investigated by appointment or treated in a non-urgent fashion. In the rare event of a more acute problem 'wandering' into Channel 4, it can be redirected with courtesy and without fuss into the appropriate channel and/or to the department serviced by that particular channel.

The next question to pose is 'Who makes the decision for the choice of channel for any particular patient?' Immediately the cry is for the sorter, the triage expert and one must admit that this is where the department's consultant casually officer would come into his own. However, stop to think of his job content and what it really would entail assuming that behind him are the four channels leading to appropriate emergency reception areas fully staffed and controlled by the appropriate departments to which these channels eventually and rightly lead. Honest reflection on this question would put the man behind a glass window marked 'Enquiries'. Of course, arguments will be raised to support his more direct control of perhaps Channels 2, 3 and 4 but perhaps not Channel 1 . This might indeed be acceptable for very small areas and hospitals but in general it is tantamount to the preservation and the propping up of the existing pernicious system in which those departments receiving emergency cases have abrogated their responsibility for reception of such cases.

In order to appreciate the actual job content of the so-called triage expert, let us use the basic principles of systems analysis and decision theory to resolve the task into its basic components.

Analysis of those basic components of the sorter's task taken to its sublime or ridiculous conclusion, depending on your choice of prejudice, is set out in Fig. 1. Despite the risk of outcries from the sceptical and the pragmatic, this flow chart reveals the task of triage in a properly organized and staffed emergency reception area, for what it really is. Is this a career?

Clearly, the public are, despite medical and political opinion, capable of basic decision theory.
They demonstrate this daily in the London tube, in the stations, bus stops, restaurants, toy shops and sweetshops of the nation. In point of fact, the problem relating to the increase of casual attenders in hospital is the result of the public exerting decision theory. They have found the general practitioners are not readily available so they have presented themselves to a hospital which they have deduced, quite rightly, is always staffed. Bully for them!

Despite the risk of being accused that selfdiagnosis is a delusion, I submit, in all sincerity, and in all seriousness, that given an honest attempt by the hospital, as a corporate body, to organize and staff a four-channel reception area, then, one has the choice of solving the problem of triage by either the appointment of a consultant at $£ 6500$ per year or by having the Ministry of Public Works design a directional system based on Fig. 1.

\section{Staffing}

Having devised the basic organizational model for the reception of unheralded attendances at hospital, we must now consider the problem of staffing these channels. Admittedly, there will be difficulties even in the best organization chiefly because of an absolute shortage of medical practitioners. However, there are ways of using our present manpower resources to provide a better and more exciting service.

In the staffing of the reception areas for each Channel, the aim must be job satisfaction and the development of junior staff 'on the floor'. There is no need for extensive and expensively trained consultants to sit in the casualty department. Given a proper staff line management relationship with excellent built-in delegation and control systems, the junior staff will provide an interested and informed service.

All this infers that the staffing of the emergency area of Channel 1 will be carried out by the orthopaedic and accident service department. Those staffing it, at all levels, must have a clear rotation through the controlling department or at least career guidance counselling within that department.

Similarly, Channels 2 and 3 will be staffed by Medical and Surgical Departments who will ensure that the reception area staff are an integral part of the career structure of their respective departments.

Channel 4 , which receives the general practice type of attender, will be staffed in teaching hospitals by the departments of general practice, aided by the department of internal medicine. In other areas, it will be staffed by a pool of resident staff, on rotation and on a mandatory basis, from all departments and, under the supervision and direction of 


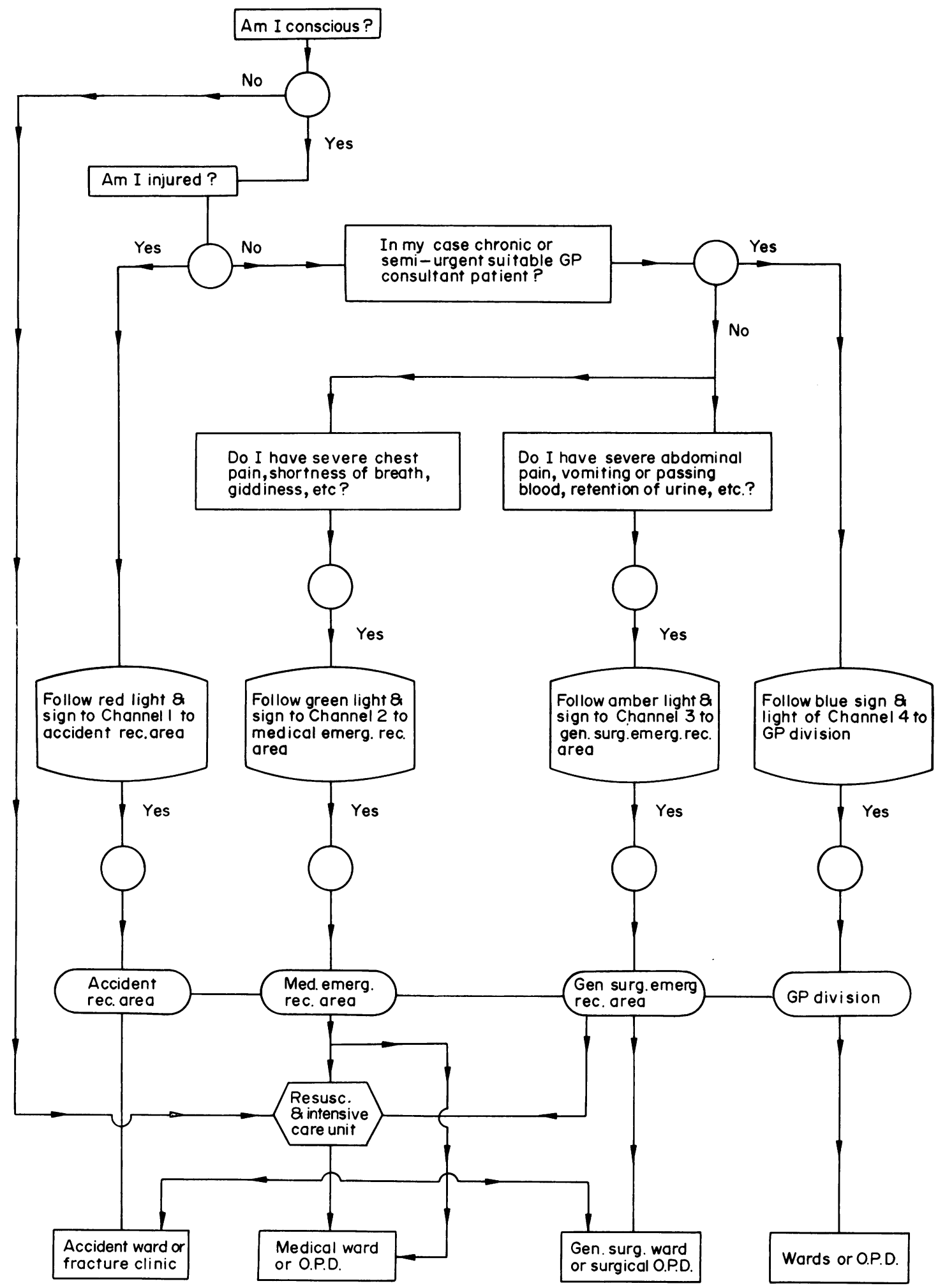

FIG. 1. Idiot proof flow chart for triage of unheralded attendance at hospital. 
either a general physician or a hospital general practitioner.

This scheme of staffing emergency reception areas, Channels 1, 2, 3, and 4, will abolish for ever the post of casualty officer and ensure that all departments are responsible for staffing the reception areas relating to their own departments and that, where it arises, the general practice side of a hospital is dealt with either by a special general practitioner department, or on rotation by departments under the direction of the department of internal medicine.

In teaching and large provincial hospitals, currently employing pre-registration doctors, staffing can be heiped considerably, and particularly in Channel 4, by ensuring that a period spent in a reception area is mandatory for registration. This is the case in the United States, Australia and New Zealand and it is time that such rotating internships were introduced into the United Kingdom to replace the outdated and outmoded pre-registration posts of 6 months medicine and 6 months surgery.

Thus, it will be seen that the organization and staffing of hospitals, so as to meet the demands of those seeking, unheralded, assistance within its portals, can be met only by a complete re-organiza- tion of the present system, assumption of appropriate responsibilities by each department, as a corporate body, the establishment of a crisp organizational pattern, and the deployment of manpower recources to meet this pattern, whilst still retaining responsibility and concern for the career structure and the development of men and women holding these junior posts on the 'shop floor' in the reception areas, whether these be Channels $1,2,3$ or 4 .

I am honoured to have been afforded the opportunity of writing the conclusions to this symposium. They are conclusions, and a personal suggested solution, written after careful analysis of all the papers, discussions, etc. I have attempted to consider fairly the contributions of all speakers and finally to expose the bones of the problem in the terms of a simple management survey.

In closure, I should draw attention to the fact that the concept and organization of this symposium is a manifestation of the quality and integrity of men in training who are concerned that the accident and emergency services of the nation will ke managed and staffed on rational rather than tired traditional lines. The institution supports and is proud of their efforts. 